\title{
Thermal Decomposition Study of Ferrocene $\left[\left(\mathrm{C}_{5} \mathrm{H}_{5}\right)_{2} \mathrm{Fe}\right]$
}

\author{
Ashis Bhattacharjee, ${ }^{1}$ Amlan Rooj, ${ }^{1}$ Debasis Roy, ${ }^{1}$ and Madhusudan Roy ${ }^{2}$ \\ ${ }^{1}$ Department of Physics, Visva-Bharati University, Santiniketan 731235, India \\ ${ }^{2}$ Surface Physics and Material Science Division, Saha Institute of Nuclear Physics, Kolkata 700064, India \\ Correspondence should be addressed to Ashis Bhattacharjee; ashis.bhattacharjee@visva-bharati.ac.in
}

Received 19 December 2013; Accepted 14 March 2014; Published 27 April 2014

Academic Editor: Ahmad Ibrahim

Copyright (C) 2014 Ashis Bhattacharjee et al. This is an open access article distributed under the Creative Commons Attribution License, which permits unrestricted use, distribution, and reproduction in any medium, provided the original work is properly cited.

A single-step thermal decomposition of ferrocene $\left[\left(\mathrm{C}_{5} \mathrm{H}_{5}\right)_{2} \mathrm{Fe}\right]$ using nonisothermal thermogravimetry (TG) has been studied using single- as well as multiple-heating rate programs. Both mechanistic and nonmechanistic methods have been used to analyze the TG data to estimate the kinetic parameters for the solid state reaction. Two different isoconversional methods (improved iterative method and model-free method) have been employed to analyze the TG results to find out whether the activation energy of the reaction depends on the extent of decomposition and to predict the most probable reaction mechanism of thermal decomposition as well. A comparison of the activation energy values for the single-step thermal reaction of ferrocene estimated by different methods has been made in this work. An appraisal on the applicability of single-heating rate data for the analysis of single-step thermal decompositions over the recommendations by the International Confederation for Thermal Analysis and Calorimetry (ICTAC) is made to look beyond the choice.

\section{Introduction}

In recent times, the organometallic compound ferrocene, $\left[\left(\mathrm{C}_{5} \mathrm{H}_{5}\right)_{2} \mathrm{Fe}\right]$, has become an important precursor material for preparing iron oxide nanostructures through thermal decomposition, for example, ferromagnetic micro/ nanoparticles [1-3], iron oxide thin films [4], and singlewalled/ferromagnetic-filled carbon nanotube $[5,6]$. Taking leaf out of these works, we undertake to study the thermal decomposition of ferrocene materials in the presence of guest molecules of various kinds leading to iron oxides and to investigate the correlation among the thermal decomposition reaction kinetics, morphology/physical characteristics of the reaction products, and the nature of the guest molecules. As a prerequisite, we undertake to study the kinetics of thermal decomposition reaction of one such precursor material, ferrocene, in order to find the reaction kinetic parameters as well as the most probable mechanism. To the best of our knowledge there is only one report on the thermal decomposition study of ferrocene [7], which, however, does not discuss the reaction mechanism.
There are two basic approaches to determine the reaction kinetic parameters or kinetic triplets (activation energy, frequency factor or rate of reaction, and most probable reaction mechanism function $g(\alpha)$ ) related to thermal decomposition using the thermogravimetry (TG) data-(a) mechanistic and (b) nonmechanistic [8]. At the beginning of the present TG data analysis we have utilized the wellknown classic equations of Freeman-Carroll [9], Kissinger [10], and Lozano et al. [11] to estimate kinetic parameters related to the thermal decomposition of ferrocene. In addition, Arrhenius equation [12] has been used to identify the most probable reaction mechanism function. Besides the Kissinger method [10], all other methods require single-heating rate-based TG data. Most importantly, the basic assumption for these methods is that the activation energy of decomposition reaction is unique and it does not depend on the extent of thermal decomposition at any instant of time. But as per the recommendation of the kinetics committee of the International Confederation for Thermal Analysis and Calorimetry (ICTAC), the multiple temperature program methods should be used 
to evaluate the reaction kinetic parameters reliably [13]. Accordingly, two multiheating rate methods, called isoconversional methods, namely, improved iterative method [14] and model-free method [15], are also employed to analyze the present TG data. The modern kinetics investigation procedure using multiheating rates is used to find out the most probable reaction mechanism function as well [16].

In the present paper, we have reported the thermal decomposition study of ferrocene by thermogravimetry. Our aim is, on one hand, to estimate the reaction kinetic parameters based on the mathematical analysis of thermogravimetric profiles of ferrocene and, on the other hand, to discuss the variation of activation energy values (estimated by various methods) with the extent of thermal decomposition to reveal the applicability of the methods based on single-heating rate over the ICTAC recommendation for single-step solid state thermal reactions.

\section{Experimental}

2.1. Materials and Measurement. The material for the present study is ferrocene $\left[\left(\mathrm{C}_{5} \mathrm{H}_{5}\right)_{2} \mathrm{Fe}\right]$. The high quality material was procured from Sigma and used without further purification. Nonisothermal thermogravimetry (TG) measurements were carried out using a thermogravimetry analyzer (Netzsch, Germany, model: STA 449C). The sample and reference crucibles used for measurements are made of alumina. The sample of $\sim 4 \mathrm{mg}$ mass was scanned at constant heating rates $\left(5,10,15\right.$, and $\left.20 \mathrm{~K} \mathrm{~min}^{-1}\right)$ in (room) air environment. UHP nitrogen (99.999\%) was used as protective gas in the instrument.

2.2. Kinetic Calculations. To determine the activation energy of solid state thermal decomposition reaction of ferrocene using nonmechanistic methods, two equations proposed by Freeman-Carroll [9] and Kissinger [10] are used first. Freeman-Carroll equation is given by

$$
\ln W=\frac{E^{*}}{R T}+\ln \left(\frac{r_{d}}{A}\right),
$$

where $W$ is the remaining mass fraction in a TG curve that represents the thermal decomposition at a constant heating rate at any instant of time, $E^{*}$ is the activation energy, $R$ is the universal gas constant, $T$ is the temperature in absolute scale, $r_{d}$ is thermal decomposition rate, and $A$ is the preexponential factor. Using (1) the activation energy value of the thermal decomposition can be estimated from the slope of the $\ln W$ versus $1 / T$ plot.

The nonmechanistic Kissinger equation [10] is given by

$$
\ln \left(\frac{\beta}{T_{P}^{2}}\right)=-\frac{E^{*}}{R T}+\ln \left(\frac{A R}{E^{*}}\right),
$$

where $\beta$ is the linear heating rate, $T_{p}$ is the differential thermogravimetry peak temperature in absolute scale, and other symbols have their usual meaning. To apply Kissinger's method, the TG profiles with different heating rates are required. Employing (2), the activation energy values of the thermal decomposition process can be calculated from the slope of the $\ln \left(\beta / T_{P}^{2}\right)$ versus $-1 / T$ plot.

In order to find out the nonisothermal reaction kinetic model describing the thermal decomposition process, the following mechanistic equation is used to identify the mechanism of reaction according to Lozano et al. [11]:

$$
\frac{\Delta \ln \alpha^{\prime}}{\Delta \ln (1-\alpha)}=-\frac{E^{*}}{R} \frac{\Delta(1 / T)}{\Delta \ln (1-\alpha)}+\frac{\Delta \ln f(\alpha)}{\Delta \ln (1-\alpha)}
$$

where $\alpha=\left(m_{i}-m_{t}\right) /\left(m_{i}-m_{f}\right)$ is the extent of reaction or conversion, that is, the fraction of material reacted in time $t$, with $m_{i}$ and $m_{f}$ being the initial and final masses, respectively; $m_{t}$ is the mass at any instant of reaction, $\alpha^{\prime}=d \alpha / d T$, and $f(\alpha)$ is the kinetic differential mechanism function which determines the actual reaction mechanism. A series of proposed forms of $f(\alpha)$ are available in [17]. A plot of $\left(\left(\Delta \ln \alpha^{\prime}-\Delta \ln f(\alpha)\right) / \Delta \ln (1-\alpha)\right)$ versus $\Delta(1 / T) / \Delta \ln (1-$ $\alpha$ ) will be a straight line with a slope $-E^{*} / R$, irrespective of the form of $f(\alpha)$ employed. The form of the function $f(\alpha)$ is selected in such a way that it best fits the actual mechanism of the reaction corresponding to the intercept value and the correlation coefficient close to zero and unity, respectively. The reaction kinetic parameters for the thermal decomposition are thus estimated. To identify the actual mechanism of the reaction kinetic process and to test the correctness of the validity of conclusions drawn using (3), the Arrhenius equation of the following type is used [12]:

$$
\ln \alpha^{\prime}-\ln f(\alpha)=\ln \left(\frac{A}{\beta}\right)-\frac{E^{*}}{R T},
$$

where $\alpha^{\prime}=d \alpha / d T, A$ is the Arrhenius parameter, and the remaining symbols have their usual meaning. The plot of $\left[\ln \alpha^{\prime}-\ln f(\alpha)\right]$ versus $1 / T$ is expected to be a straight line when the Arrhenius equation is applicable, and from its slope and intercept the values of $E_{\alpha}^{*}$ and $A$ are estimated, respectively. Now, if the proposed mechanism on the basis of (3) is correct, the activation energy values estimated from (4) should in principle be the same or close to those obtained using (3) [12]. According to this paradigm, the most probable mechanism function $f(\alpha)$ using TG data can be determined [17].

To describe the reaction kinetics and mechanism of thermal decomposition of solids most reliably, isoconversional (model-free) methods are presently often used. In isoconversional method, the reaction rate at constant extent of conversion is supposed to be a function of temperature only. Two simplifying assumptions are mostly used in this regard: (i) the temperature at any point in the solid remains the same and (ii) the controlling step in the reaction rate does not alter throughout the transformation of a solid state chemical process $[18,19]$. In order to study the kinetics of solid state reaction under nonisothermal conditions with linear heating rates $(\beta)$ two early basic equations used as regards thermal decomposition are Flynn-Wall-Ozawa (FWO) [20, 
21] and Kissinger-Akahira-Sunose (KAS) [10, 22] equations. The FWO equation is expressed as

$$
\ln \beta_{i}=\ln \frac{0.0048 A_{\alpha} E_{\alpha}^{*}}{g(\alpha) R}-1.052 \frac{E_{\alpha}^{*} A_{\alpha}}{R T_{\alpha, i}}
$$

and the KAS equation is written as

$$
\ln \frac{\beta_{i}}{T_{\alpha, i}^{2}}=\ln \frac{A_{\alpha} R}{g(\alpha) E_{\alpha}^{*}}-\frac{E_{\alpha}^{*}}{R T_{\alpha, i}},
$$

where the subscript " $i$ " denotes different heating rates and $T_{\alpha, i}$ is the temperature at which an extent of reaction $(\alpha)$ is reached at constant heating rate $\left(\beta_{i}\right)$ and $E_{\alpha}^{*}$ is the activation energy for a given $\alpha$ and $g(\alpha)=\int_{0}^{\alpha}[f(\alpha)]^{-1} d \alpha$. The activation energy values obtained by (5) and (6) are often found less accurate. To calculate the activation energy more accurately, the iterative procedure approximating the exact value of activation energy is used [14] according to the following equations:

$$
\begin{gathered}
\ln \frac{\beta_{i}}{h(x) T_{\alpha, i}^{2}}=\ln \frac{A_{\alpha R}}{g(\alpha) E_{\alpha}^{*}}-\frac{E_{\alpha}^{*}}{R T_{\alpha, i}}, \\
\ln \frac{\beta_{i}}{H(x)}=\ln \frac{0.0048 A_{\alpha} E_{\alpha}^{*}}{g(\alpha) R}-1.0516 \frac{E_{\alpha}^{*} A_{\alpha}}{R T_{\alpha, i}},
\end{gathered}
$$

where $h(x)$ is expressed as [23]

$$
h(x)=\frac{x^{4}+18 x^{3}+88 x^{2}+96 x}{x^{4}+20 x^{3}+120 x^{2}+240 x+120}
$$

and $H(x)$ is expressed as [16]

$$
H(x)=\frac{\exp (-x) h(x) / x^{2}}{0.0048 \exp (-1.0516 x)},
$$

where $x=E_{\alpha}^{*} / R T_{\alpha, i}$.

In performing the iterative procedure the following steps are often used: step 1-the initial value of the activation energy $\left(E_{\alpha}^{*}\right)_{1}$ is estimated by assuming $h(x)=1$ or $H(x)=$ 1 (generally, the conventional isoconversional methods stop calculating at this step); step 2-using $E_{\alpha}^{*}=\left(E_{\alpha}^{*}\right)_{1}$ the new value of activation energy, another value of $E_{\alpha}^{*}=$ $\left(E_{\alpha}^{*}\right)_{2}$ is calculated from the plot $\ln \left(\beta_{i} / H(x)\right)$ versus $1 / T_{\alpha, i}$ or $\ln \left(\beta_{i} / h(x) T_{\alpha, i}^{2}\right)$ versus $1 / T_{\alpha, i}$; step 3 -repeat of step 2 replacing $\left(E_{\alpha}^{*}\right)_{1}$ with $\left(E_{\alpha}^{*}\right)_{2}$ resulting $E_{\alpha}^{*}=\left(E_{\alpha}^{*}\right)_{3}$, and so on until the absolute difference of $\left[\left(E_{\alpha}^{*}\right)_{i}-\left(E_{\alpha}^{*}\right)_{i-1}\right]$ becomes less than $0.1 \mathrm{~kJ} \mathrm{~mole}^{-1}$ [17]. The last value of $\left(E_{\alpha}^{*}\right)_{1}$ thus obtained is considered to be the more exact value of the activation energy of the thermal decomposition reaction. The activation energy evaluated by this method is reaction-model independent and usually regarded as more reliable [14].

In the model-free isoconversional method for nonisothermal thermogravimetry experiments, the activation energy $E_{\alpha}^{*}$ can be evaluated at any particular value of $\alpha$ by minimizing the following objective function $[15,24]$ :

$$
\Omega\left(E_{\alpha}^{*}\right)=\sum_{i=1}^{n} \sum_{\substack{j=1 \\ i \neq j}}^{n} \frac{I\left(E_{\alpha}^{*}, T_{\alpha, i}\right) \beta_{j}}{I\left(E_{\alpha}^{*}, T_{\alpha, j}\right) \beta_{i}},
$$

where $I\left(E_{\alpha}^{*}, T_{\alpha, i}\right)$ the temperature integral is given as

$$
I\left(E_{\alpha}^{*}, T_{\alpha, i}\right)=\int_{0}^{T_{\alpha, i}} \exp \left(-\frac{E_{\alpha}^{*}}{R T}\right) d T .
$$

There are several methods and popular approximations to evaluate this temperature integral. Approximation of Cai et al. [25], which is proved to be superior to any other approximations, is mostly used for evaluation of activation energy $E_{\alpha}^{*}$ and other kinetic parameters from nonisothermal kinetic analysis of the TG data. According to this approximation the temperature integral is given as

$$
\begin{aligned}
& \int_{0}^{T_{\alpha, i}} \exp \left(-\frac{E_{\alpha}^{*}}{R T}\right) d T \\
& \quad=\frac{R T_{\alpha, i}^{2}}{E_{\alpha}^{*}}\left[\frac{\left(E_{\alpha}^{*} / R T_{\alpha, i}\right)+0.66691}{\left(E_{\alpha}^{*} / R T_{\alpha, i}\right)+2.64943}\right] \exp \left(-\frac{E_{\alpha}^{*}}{R T_{\alpha, i}}\right) .
\end{aligned}
$$

The equation which is mostly used to estimate the most probable reaction mechanism, that is, $g(\alpha)$ function, is given as [16]

$$
\ln g(\alpha)=\left[\ln \frac{A_{\alpha} E_{\alpha}^{*}}{R}+\ln \frac{e^{-x}}{x^{2}}+\ln h(x)\right]-\ln \beta_{i},
$$

where $g(\alpha)=\int_{0}^{\alpha}[f(\alpha)]^{-1} d \alpha=(A / \beta) \int_{0}^{T} \exp \left(E^{*} / R T\right) d T$ is the integral form of the reaction model describing the reaction mechanism $[17,18]$ and the other symbols have their usual meaning. For the determination of the most probable mechanism function, the slope of the straight line of $\ln g(\alpha)$ versus $\ln \beta_{i}$ plot, using linear regression of least square method, should be nearly equal to -1.0000 and the linear correlation coefficient $R^{2}$ should be nearly equal to unity [17]. While finding the most probable reaction mechanism function $g(\alpha)$ involved in the present thermal decomposition reaction, the 35 types of mechanism function given in [17] have been used. If incidentally a number of $g(\alpha)$ functions satisfy the conditions specified above, the values of the extent of reaction, $\alpha$ corresponding to multiple-heating rates at a temperature but other than the previous one along the $\alpha$ versus $T$ plots are applied to confirm the most probable reaction mechanism function by the same way.

Using the estimated value of the activation energy and the most probable reaction mechanism function, the preexponential or frequency factor $(A)$ value can be evaluated from the following equation $[17,26]$ :

$$
A=-\frac{\beta x_{p}}{T f^{\prime}\left(\alpha_{p}\right)} \exp \left(x_{p}\right),
$$

where $x_{p}=E^{*} / R T_{p}\left(T_{p}\right.$ is the peak temperature on corresponding differential thermogravimetry curve) and $f^{\prime}\left(\alpha_{p}\right)$ is the first derivative of the reaction mechanism function.

2.3. Thermodynamic Parameters. From the theory of the activated complex (transition state) of Eyring [27-30], the following general equation may be written:

$$
A=\frac{e \chi k_{B} T_{p}}{h \exp \left(\Delta S^{*} / R\right)},
$$


where $e=2.7183$ (base of natural logarithms), $\chi$ is the transition factor ( $=1$ for monomolecular reactions), $k_{B}$ is the Boltzmann constant, $h$ is Plank's constant, and $T_{p}$ is the peak temperature of the differential thermogravimetry curve at the corresponding step. The change of the entropy $\Delta S^{*}$ may be calculated according to the following formula:

$$
\Delta S^{*}=R \ln \left(\frac{A h}{e \chi k_{B} T_{p}}\right) .
$$

Since

$$
\Delta H=E^{*}-R T_{p},
$$

the changes of the enthalpy $\Delta H^{*}$ and Gibbs free energy $\Delta G^{*}$ for the activated complex formation from the precursor can be calculated using the well-known thermodynamical equation:

$$
\Delta G^{*}=\Delta H^{*}-T_{p} \Delta S^{*}
$$

The values of $\Delta S^{*}, \Delta H^{*}$, and $\Delta G^{*}$ are calculated at $T_{p}$, since this temperature characterizes the highest rate of decomposition.

The calculations of reaction kinetic parameters, using the above-stated equations, were based on a program compiled in MATLAB.

\section{Results and Discussion}

Figure 1 shows the TG profiles of ferrocene obtained under four different heating rates $\left(5,10,15\right.$, and $\left.20 \mathrm{~K} \mathrm{~min}^{-1}\right)$. Each TG profile confirms a one-step decomposition process for this material and represents the relationship of the residual mass with temperature during thermal decomposition. However, this decomposition takes place in temperature ranges $349-465 \mathrm{~K}, 345-485 \mathrm{~K}, 356-498 \mathrm{~K}$, and $385-511 \mathrm{~K}$ for $5,10,15$, and $20 \mathrm{~K} \mathrm{~min}^{-1}$ heating rates, respectively, and the thermal reaction becomes maximum at $\sim 448 \mathrm{~K}$ in all cases of heating rates and is completed with almost $\sim 100 \%$ mass loss beyond $\sim 510 \mathrm{~K}$. Melting point of ferrocene is $448 \mathrm{~K}$. Ferrocene $\left(\mathrm{C}_{5} \mathrm{H}_{5}\right)_{2} \mathrm{Fe}$ has a "sandwich structure" of two parallel cyclopentadienyl rings with an iron in the center between these rings. It is solid at room temperature and thermally decomposes at $448 \mathrm{~K}$ and its boiling point is $522 \mathrm{~K}$. In the temperature range from $\sim 870 \mathrm{~K}$ to $\sim 1420 \mathrm{~K}$ ferrocene further decomposes [31]. According to Leonhardt et al. [6], at temperatures above $\sim 770 \mathrm{~K}$, gaseous ferrocene decomposes spontaneously to form metallic iron according to the following reaction:

$$
\left(\mathrm{C}_{5} \mathrm{H}_{5}\right)_{2} \mathrm{Fe} \longrightarrow \mathrm{Fe}+\mathrm{H}_{2}+\mathrm{CH}_{4}+\mathrm{C}_{5} \mathrm{H}_{6}+\cdots .
$$

This means that in this temperature range solid or liquidlike Fe particles and different kinds of hydrocarbons may exist in the reaction medium. Thus, the presently observed thermal decomposition indicates that the sublimation of ferrocene which takes place during solid state reaction and no further conversion to liquid or solid Fe has been observed as no increase in mass has been recorded in the TG profile.

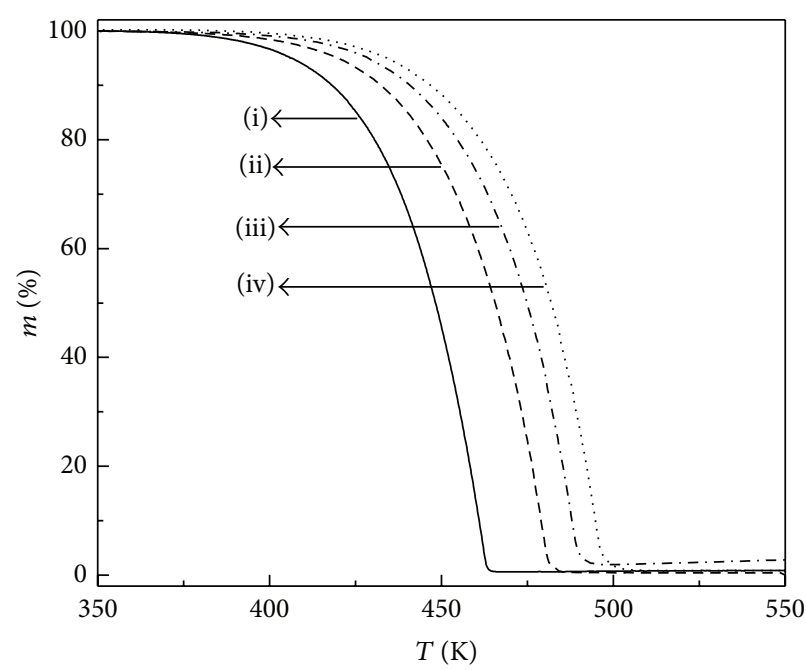

FIGURE 1: Thermogravimetric profiles of ferrocene obtained under different heating rates: (i) $5 \mathrm{~K} \mathrm{~min}^{-1}$, (ii) $10 \mathrm{~K} \mathrm{~min}^{-1}$, (iii) $15 \mathrm{~K} \mathrm{~min}^{-1}$, and (iv) $20 \mathrm{~K} \mathrm{~min}^{-1}$.

At this point it has to be noted that TG deals with a very small amount of sample mass. At higher temperatures when the further conversion of sublimated ferrocene to liquid or solid Fe takes place, it is quite unlikely to be detected by the TG considering the converted sample mass as well as the presently used sample cell geometry.

Utilizing the TG data of the thermal decomposition of ferrocene, the activation energy values for the single-step reaction process were calculated from the slope of (i) the $\ln W$ versus $1 / T$ plot using (1) and of (ii) the $\ln \left(\beta / T_{P}^{2}\right)$ versus $-1 / T$ plot using (2) and are shown in Table 1. Again combining (3) and (4), the kinetic parameters for the decomposition of ferrocene were estimated and are presented in Table 1. According to (3) and (4) the most probable mechanism function $f(\alpha)$ using the TG data of ferrocene has been determined to be three-dimensional diffusion type which can be represented by $f(\alpha)=3 / 2\left[(1-\alpha)^{-1 / 3}-1\right]^{-1}$ [17]. The $E_{\alpha}^{*}$ values obtained from the multiheating rate TG data using (7) and (8) are also compared in Table 1. The temperature variations of the extent of reaction $\alpha=\left(m_{i}-m_{t}\right) /\left(m_{i}-m_{f}\right)$ during thermal decomposition of ferrocene under different heating rates are illustrated in Figure 2. The minimization procedure according to (11)-(13) was repeated for each value of $\alpha$ for 0.1 to 0.9 taking data from Figure 2 to find out the dependency of $E_{\alpha}^{*}$ on $\alpha$. The $\alpha$-dependent $E_{\alpha}^{*}$ values thus obtained are presented in Table 1.

The activation energy $E_{\alpha}^{*}$ values for the single-step thermal decomposition of ferrocene obtained by all methods discussed so far are shown as a function of the extent of conversion $\alpha$ in Figure 3. It is noticeable that the $E_{\alpha}^{*}$ values thus calculated by the three different methods given by (7), (8), and (13) are remarkably identical and are also close to that obtained by (1). At this point it should be recalled that de Souza et al. [7] observed three activation energies for the single-step thermal decomposition of ferrocene using Freeman-Carroll method which are 66.7, 71.2, and 
TABLE 1: Values of the activation energy $(E)$ estimated following different equations and the frequency factor $(A)$ for different heating rates $(\beta)$ for thermal decomposition of ferrocene.

\begin{tabular}{|c|c|c|c|c|c|c|c|c|c|c|c|}
\hline \multirow{2}{*}{$\alpha^{\#}$} & \multicolumn{7}{|c|}{ Activation energy, $E / \mathrm{kJ} \cdot \mathrm{mole}^{-1}$} & \multicolumn{4}{|c|}{ Frequency factor $A / \mathrm{min}^{-1}$} \\
\hline & $(1)$ & (2) & (3) & $(4)$ & $(7)$ & $(8)$ & $(13)$ & $\beta=5 / \mathrm{K} \mathrm{min}^{-1}$ & $\beta=10 / \mathrm{Kmin}^{-1}$ & $\beta=15 / \mathrm{K} \mathrm{min}^{-1}$ & $\beta=20 / \mathrm{K}_{\min }^{-1}$ \\
\hline 0.1 & & & & & 68.01 & 68.01 & 68.02 & $2.3 \times 10^{4}$ & $2.29 \times 10^{4}$ & $2.41 \times 10^{4}$ & $2.33 \times 10^{4}$ \\
\hline 0.2 & & & & & 67.66 & 67.66 & 67.68 & $8.11 \times 10^{4}$ & $8.09 \times 10^{4}$ & $8.54 \times 10^{4}$ & $8.25 \times 10^{4}$ \\
\hline 0.3 & & & & & 66.34 & 66.34 & 66.36 & $1.24 \times 10^{5}$ & $1.25 \times 10^{5}$ & $1.33 \times 10^{5}$ & $1.28 \times 10^{5}$ \\
\hline 0.4 & & & & & 66.42 & 66.42 & 66.44 & $2.22 \times 10^{5}$ & $2.24 \times 10^{5}$ & $2.37 \times 10^{5}$ & $2.28 \times 10^{5}$ \\
\hline 0.5 & 64.18 & 88.6 & 77.6 & 87.7 & 66.42 & 66.42 & 66.44 & $3.43 \times 10^{5}$ & $3.45 \times 10^{5}$ & $3.66 \times 10^{5}$ & $3.51 \times 10^{5}$ \\
\hline 0.6 & & & & & 67.21 & 67.21 & 67.23 & $6.06 \times 10^{5}$ & $6.04 \times 10^{5}$ & $6.39 \times 10^{5}$ & $6.16 \times 10^{5}$ \\
\hline 0.7 & & & & & 67.40 & 67.40 & 67.40 & $8.55 \times 10^{5}$ & $8.51 \times 10^{5}$ & $9.00 \times 10^{5}$ & $8.69 \times 10^{5}$ \\
\hline 0.8 & & & & & 69.41 & 69.41 & 69.42 & $1.92 \times 10^{6}$ & $1.88 \times 10^{6}$ & $1.97 \times 10^{6}$ & $1.93 \times 10^{6}$ \\
\hline 0.9 & & & & & 68.34 & 68.34 & 68.35 & $1.80 \times 10^{6}$ & $1.77 \times 10^{6}$ & $1.87 \times 10^{6}$ & $1.81 \times 10^{6}$ \\
\hline
\end{tabular}

\# $\alpha$ : extent of conversion.

Note: $A=1.87 \times 10^{5}$ from (1) and $1.05 \times 10^{8}$ from (4).

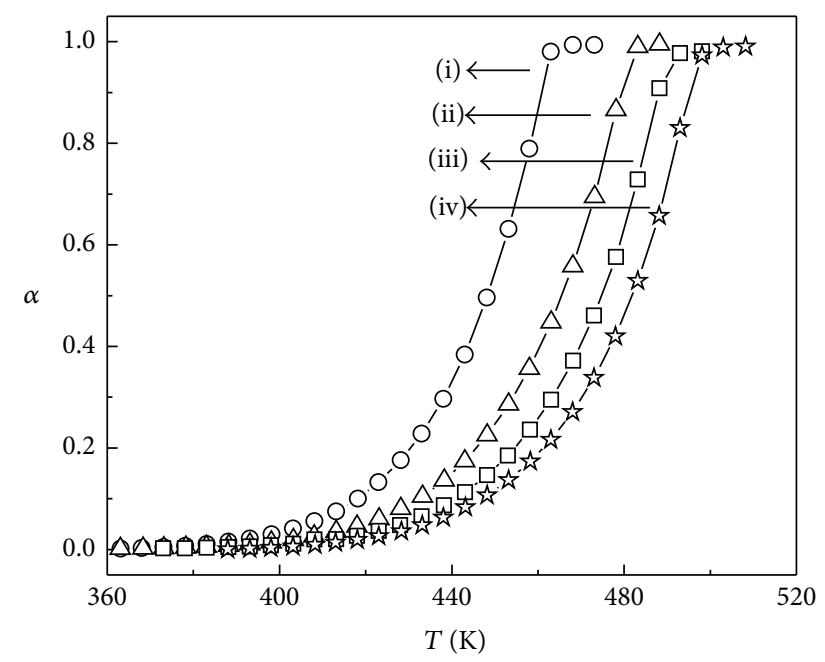

FIGURE 2: Variation of the extent of conversion of mass $(\alpha)$ with temperature during thermal decomposition of ferrocene for different heating rates: (i) $5 \mathrm{~K} \mathrm{~min}^{-1}$, (ii) $10 \mathrm{~K} \mathrm{~min}^{-1}$, (iii) $15 \mathrm{~K} \mathrm{~min}^{-1}$, and (iv) $20 \mathrm{~K} \mathrm{~min}^{-1}$.

$86.5 \mathrm{~kJ} \mathrm{~mole}^{-1}$. It has to be noted that the $E_{\alpha}^{*}=66.7 \mathrm{~kJ} \mathrm{~mole}^{-1}$ value is the same as the one determined using (1), (7), (8), and (13), whereas the $E_{\alpha}^{*}=71.2 \mathrm{~kJ} \mathrm{~mole}^{-1}$ is close to that obtained using (3) and the other $E_{\alpha}^{*}=86.5 \mathrm{~kJ} \mathrm{~mole}^{-1}$ value is close to that obtained from (2) and (4). The analysis based on the isoconversional methods could successfully detect any dependence of $E_{\alpha}^{*}$ on $\alpha$ in the present studies.

Some of the frequently used reaction mechanisms operating in solid state reactions are given in [17, 23]. Equation (14) is used to estimate the most probable reaction mechanism function $g(\alpha)$ using the multiheating rate-dependent TG data for ferrocene. The $g(\alpha)$ value thus obtained for the thermal decomposition of ferrocene is three-dimensional diffusion type given by $g(\alpha)=1+2 \alpha / 3-(1+\alpha)^{2 / 3}$ or $f(\alpha)=3 / 2\left[(1+\alpha)^{-1 / 3}-1\right]^{-1}$. It is interesting to note that according to (3) a three-dimensional diffusion has also been

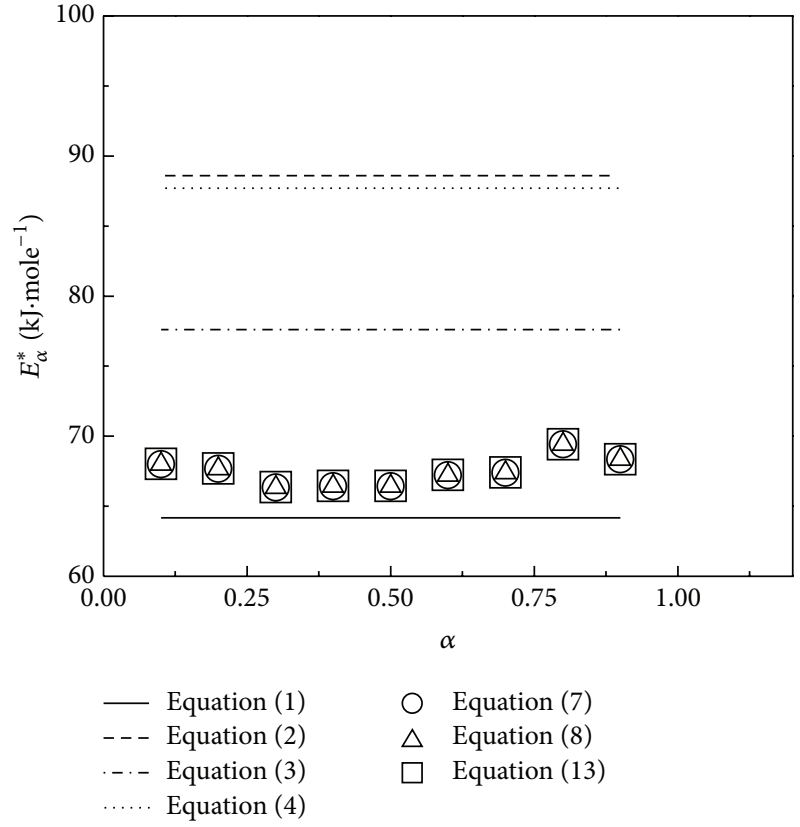

FIgURE 3: Dependence of activation energy $\left(E_{\alpha}^{*}\right)$ on the extent of conversion $(\alpha)$ of ferrocene obtained using different methods.

held responsible as the reaction mechanism for the thermal decomposition of ferrocene but represented by a different function $f(\alpha)=3 / 2\left[(1-\alpha)^{-1 / 3}-1\right]^{-1}$.

Using the values of the activation energy and the most probable reaction mechanism function estimated for ferrocene in (15), the value of frequency factor $(A)$ for different values of $\alpha$ as well as for different heating rates has been estimated (see Table 1). The variation of the average values of $A$ estimated for different heating rates is shown in Figure 4. The effect of heating rate on the $A$ value is found not to be remarkable. However, the dependence of $A$ on the $\alpha$ values is quite appreciable. It is noted that the rate of reaction for the decomposition of ferrocene varies in the range of $10^{4} \sim$ $10^{6} \mathrm{~min}^{-1}$. Interestingly, the observed dependence of $A$ value 


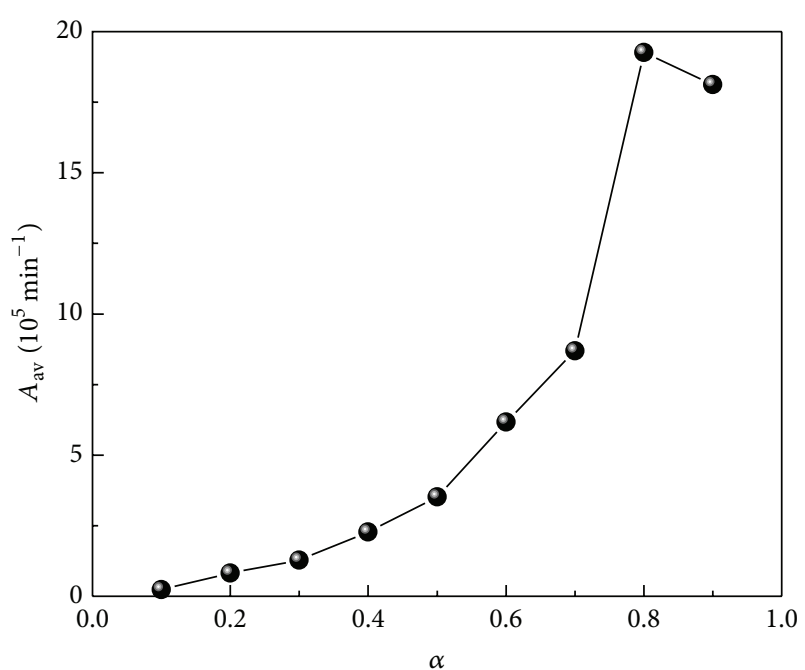

FIGURE 4: Dependence of the frequency factor $\left(A_{\mathrm{av}}\right)$ averaged for different heating rates on the extent of conversion $(\alpha)$ of ferrocene.

with $\alpha$ indicates that the reaction rate cannot be assumed as a constant for the nonisothermal decomposition process of ferrocene. From Table 1 one can also note that the $A$ value determined by using (1) is $\sim 10^{5} \mathrm{~min}^{-1}$, while that from (4) is $\sim 10^{8} \mathrm{~min}^{-1}$ where the former lies well within the range determined by (15).

Figure 5 shows the variation of $A$ values as a function of $E_{\alpha}^{*}$ where one can see that compensation effect holds between $A$ and $E_{\alpha}^{*}$ values for a narrow range of $E_{\alpha}^{*}\left[66.4 \mathrm{~kJ} \mathrm{~mol}^{-1} \leq\right.$ $E_{\alpha}^{*} \leq 69.4 \mathrm{~kJ} \mathrm{~mol}^{-1}$ ]. The appearance of the compensation effect indicates that only one reaction model may be held responsible for the solid state reaction mechanism [32]. The values of $A$ in solid state reactions are expected to be in a wide range [17]. The low $A$ values often indicate a surface reaction. If the thermal reactions are not dependent on surface area, the low $A$ value indicates a "tight" complex, while the higher $A$ value indicates a "loose" complex. Therefore, in the present case the thermal decomposition reaction of ferrocene deals with a "loose" complex.

The observed $T_{p}$ values correspond to $\alpha=\sim 0.9$ in the $\alpha$ versus $T$ plots (Figure 2). Based on the estimated values of the activation energy $E^{*}$ and frequency factor $A$ for $\alpha=0.9$ for thermal decomposition of ferrocene under different heating rates (see Table 1), the thermodynamic parameters $\Delta S^{*}, \Delta H^{*}$, and $\Delta G^{*}$ for the formation of an activated complex from the precursor were calculated according to (16)-(19) and are presented in Table 2. These values are calculated at the peak temperature $T_{p}$ in the differential thermogravimetry curve for the corresponding heating rates, since this temperature characterizes the highest rate of the reaction during the single-step thermal decomposition.

As can be seen from Table 2, the values of $\Delta S, \Delta H$, and $\Delta G$ obtained under different heating rates are independent of heating rates, and thus we discuss the average values of these parameters only. The value of $\Delta S$ for ferrocene is negative. It means that the corresponding activated complex had lower entropy or a higher degree of ordering than the precursor

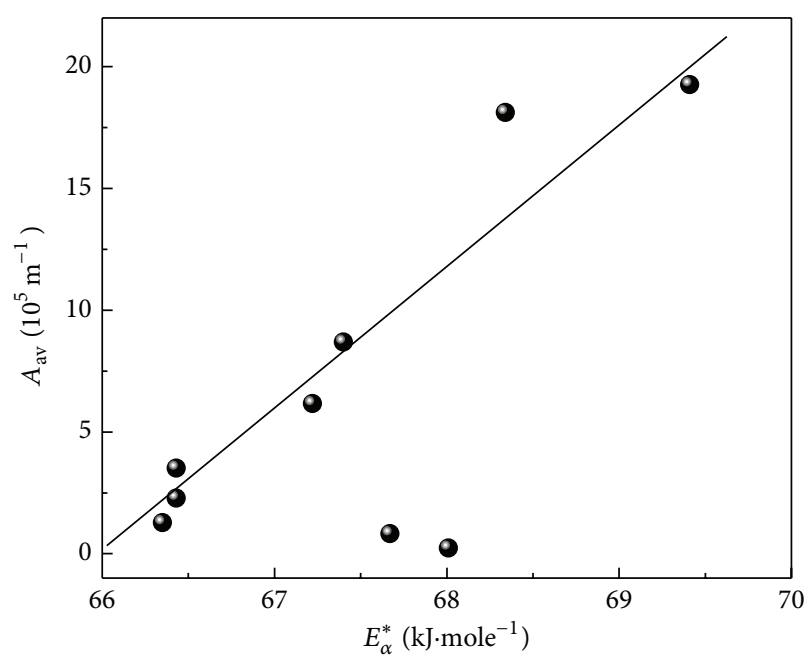

FIGURE 5: Dependence of the frequency factor $\left(A_{\text {av }}\right)$ averaged for different heating rates on the activation energy $\left(E_{\alpha}^{*}\right)$ of ferrocene.

state. Thus, if we denote the entropy of the precursor and the activated complex as $S_{0}$ and $S_{I}$, respectively, then $S_{0}>$ $S_{I}$ for thermal decomposition of ferrocene. In the terms of the theory of an activated complex [27-30], the thermal decomposition of ferrocene may be further classified into "slow" stage with negative entropy change.

\section{Conclusion}

The nonisothermal thermal decomposition of ferrocene has been represented by a single-step solid state reaction. Both mechanistic and nonmechanistic methods including singleand multiple-heating rate approaches have been utilized to analyze the TG data to estimate the reaction kinetic parameters and to identify the most probable mechanism involved in the solid state reaction. Ferrocene undergoes 100\% thermal decomposition. A comparison of the kinetic parameters for the single-step thermal decomposition reaction of ferrocene estimated here by different methods has been made. The activation energy values determined are in conformity with previously reported values. The activation energy values are found to be independent of the extent of conversion, whereas the reaction rate strongly depends on the same.

From the present analysis, it has to be noted that the activation energy and the frequency factor values determined by Freeman-Carroll equation are quite similar to that obtained by multiheating rate-dependent isoconversional methods as recommended by ICTAC. On the other hand, the reaction mechanism-three-dimensional diffusion reaction for the thermal decomposition of ferrocene predicted by Lozano et al.'s method [11] is basically similar to that obtained by using isoconversional methods following ICTAC recommendation. Thus, it seems that for single-step thermal decomposition reactions like the present one, the methods based on single-heating rate program may provide reliable kinetic parameters as obtained by multiple-heating rate programs, and thus single-heating rate-based methods could 
TABLE 2: Values of the thermodynamic parameters for thermal decomposition of ferrocene for different heating rates.

\begin{tabular}{lcccccc}
\hline$\beta / \mathrm{K}^{\prime} \mathrm{min}^{-1}$ & $T_{P} / \mathrm{K}$ & $\Delta S / \mathrm{J} \cdot \mathrm{mole}^{-1} \cdot \mathrm{K}^{-1}$ & $\begin{array}{c}\text { Average value of } \\
\Delta S / \mathrm{J} \cdot \mathrm{mole}^{-1} \cdot \mathrm{K}^{-1}\end{array}$ & $\Delta H / \mathrm{kJ} \cdot \mathrm{mole}^{-1}$ & $\begin{array}{c}\text { Average value of } \\
\Delta H / \mathrm{kJ} \cdot \mathrm{mole}^{-1}\end{array}$ & $\begin{array}{c}\Delta G / \mathrm{kJ} \cdot \mathrm{mole} \mathrm{e}^{-1} \\
\begin{array}{c}\text { Average value of } \\
\Delta G / \mathrm{kJ} \cdot \mathrm{mole}\end{array}\end{array}$ \\
\hline 5 & 462 & -171.12 & & 64.49 & & 143.56 \\
10 & 479 & -171.42 & -171.45 & 64.36 & 64.34 & 146.47 \\
15 & 488 & -171.57 & & 64.28 & & 148.01 \\
20 & 495 & -171.69 & & 64.22 & & 149.01 \\
\hline
\end{tabular}

be applicable for such single-step thermal decomposition reactions. However, this is an open question which needs to be verified for good number of such thermal decomposition reactions. It is our conjecture that the activation energy of solid state reaction in such a case is either unique or nearly independent of the extent of thermal decomposition.

Ferrocene when heated alone above $\sim 770 \mathrm{~K}$ does not produce any traceable solid material detectable in the TG profile, but when it is heated together with oxalic acid the solid hematite product is formed at $\sim 450 \mathrm{~K}$ [33]. This may imply that oxalic acid catalyzes the thermal decomposition of ferrocene. With the above results in hand, our next interest will be to control the thermal decomposition reaction of ferrocene in the presence of suitable guest molecules leading to the formation of interesting ferrite materials which are in progress.

\section{Conflict of Interests}

The authors declare that there is no conflict of interests regarding the publication of this paper.

\section{References}

[1] N. Koprinarov, M. Konstantinova, and M. Marinov, "Ferromagnetic nanomaterials obtained by thermal decomposition of ferrocene," Solid State Phenomena, vol. 159, pp. 105-108, 2010.

[2] K. Elihn, L. Landström, O. Alm, M. Boman, and P. Heszler, "Size and structure of nanoparticles formed via ultraviolet photolysis of ferrocene," Journal of Applied Physics, vol. 101, no. 3, Article ID 034311, 2007.

[3] E. P. Sajitha, V. Prasad, S. V. Subramanyam, A. K. Mishra, S. Sarkar, and C. Bansal, "Structural, magnetic and Mössbauer studies of iron inclusions in a carbon matrix," Journal of Magnetism and Magnetic Materials, vol. 313, no. 2, pp. 329-336, 2007.

[4] M. Rooth, A. Johansson, K. Kukli, J. Aarik, M. Boman, and A. Hårsta, "Atomic layer deposition of iron oxide thin films and nanotubes using ferrocene and oxygen as precursors," Chemical Vapor Deposition, vol. 14, no. 3-4, pp. 67-70, 2008.

[5] A. Barreiro, S. Hampel, M. H. Rümmeli et al., "Thermal decomposition of ferrocene as a method for production of singlewalled carbon nanotubes without additional carbon sources," The Journal of Physical Chemistry B, vol. 110, no. 42, pp. 2097320977, 2006.

[6] A. Leonhardt, S. Hampel, C. Müller et al., "Synthesis, properties, and applications of ferromagnetic-filled carbon nanotubes," Chemical Vapor Deposition, vol. 12, no. 6, pp. 380-387, 2006.

[7] A. C. de Souza, A. T. N. Pires, and V. Soldi, "Thermal stability of ferrocene derivatives and ferrocene-containing polyamides,"
Journal of Thermal Analysis and Calorimetry, vol. 70, no. 2, pp. 405-414, 2002.

[8] M. E. Brown, D. Dollimore, and A. K. Galwey, "Theory of solid state reaction kinetics," in Comprehensive Chemical Kinetics: Reactions in the Solid State, C. H. Bamford and C. H. Tipper, Eds., p. 41, Elsevier, Amsterdam, The Netherlands, 1980.

[9] E. S. Freeman and B. Carroll, "The application of thermoanalytical techniques to reaction kinetics. The thermogravimetric evaluation of the kinetics of the decomposition of calcium oxalate monohydrate," Journal of Physical Chemistry, vol. 62, no. 4, pp. 394-397, 1958.

[10] H. E. Kissinger, "Reaction kinetics in differential thermal analysis," Analytical Chemistry, vol. 29, no. 11, pp. 1702-1706, 1957.

[11] R. Lozano, J. Román, J. C. Avilés, A. Moragues, A. Jerez, and E. Ramos, "Thermal decomposition of molybdenum(IV) dialkyldithiocarbamates: application of a new method to kinetic studies," Transition Metal Chemistry, vol. 12, no. 4, pp. 289-291, 1987.

[12] N. Deb, "An investigation on the solid state pyrolytic decomposition of bimetallic oxalate precursors of $\mathrm{Ca}, \mathrm{Sr}$ and $\mathrm{Ba}$ with cobalt: a mechanistic approach," Journal of Analytical and Applied Pyrolysis, vol. 80, no. 2, pp. 389-399, 2007.

[13] S. Vyazovkin, A. K. Burnham, J. M. Criado, L. A. PérezMaqueda, C. Popescu, and N. Sbirrazzuoli, "ICTAC Kinetics Committee recommendations for performing kinetic computations on thermal analysis data," Thermochimica Acta, vol. 520, no. 1-2, pp. 1-19, 2011.

[14] Z. Gao, M. Nakada, and I. Amasaki, "A consideration of errors and accuracy in the isoconversional methods," Thermochimica Acta, vol. 369, no. 1-2, pp. 137-142, 2001.

[15] S. Vyazovkin and D. Dollimore, "Linear and nonlinear procedures in isoconversional computations of the activation energy of nonisothermal reactions in solids," Journal of Chemical Information and Computer Sciences, vol. 36, no. 1, pp. 42-45, 1996.

[16] L. Liqing and C. Donghua, "Application of ISO-temperature method of multiple rate to kinetic analysis: dehydration for calcium oxalate monohydrate," Journal of Thermal Analysis and Calorimetry, vol. 78, no. 1, pp. 283-293, 2004.

[17] L. Vlaev, N. Nedelchev, K. Gyurova, and M. Zagorcheva, "A comparative study of non-isothermal kinetics of decomposition of calcium oxalate monohydrate," Journal of Analytical and Applied Pyrolysis, vol. 81, no. 2, pp. 253-262, 2008.

[18] J. Farjas and P. Roura, "Isoconversional analysis of solid state transformations: a critical review-part II: complex transformations," Journal of Thermal Analysis and Calorimetry, vol. 105, no. 3, pp. 767-773, 2011.

[19] E. Ruiz-Agudo, J. D. Martín-Ramos, and C. Rodriguez-Navarro, "Mechanism and kinetics of dehydration of epsomite crystals 
formed in the presence of organic additives," Journal of Physical Chemistry B, vol. 111, no. 1, pp. 41-52, 2007.

[20] T. Ozawa, "A new method of analyzing thermogravimetric data," Bulletin of the Chemical Society of Japan, vol. 38, pp. 18811886, 1965.

[21] J. H. Flynn and L. A. Wall, "A quick, direct method for the determination of activation energy from thermogravimetric data," Journal of Polymer Science Part B: Polymer Letters, vol. 4, no. 5, pp. 323-328, 1966.

[22] T. Akahira and T. Sunose, "Trans joint convention of four electrical institutes, paper no. 246, 1969 research report,” Science and Technology, vol. 16, pp. 22-31, 1971.

[23] G. I. Senum and R. T. Yang, "Rational approximations of the integral of the Arrhenius function," Journal of Thermal Analysis, vol. 11, no. 3, pp. 445-447, 1977.

[24] S. Vyazovkin, "Isoconversional kinetics," in Handbook of Thermal Analysis and Calorimetry, M. E. Brown and P. K. Gallagher, Eds., Recent Advances, Techniques and Applications, pp. 503538, Elsevier, Amsterdum, The Netherlands, 2008.

[25] J. Cai, F. Yao, W. Yi, and F. He, "New temperature integral approximation for nonisothermal kinetics," AIChE Journal, vol. 52, no. 4, pp. 1554-1557, 2006.

[26] J. Málek, "The kinetic analysis of non-isothermal data," Thermochimica Acta, vol. 200, pp. 257-269, 1992.

[27] D. Young, Decomposition of Solids, Pergamon Press, Oxford, UK, 1966.

[28] H. F. Cordes, "The preexponential factors for solid-state thermal decomposition," Journal of Physical Chemistry, vol. 72, no. 6, pp. 2185-2189, 1968.

[29] J. Šesták, Thermophysical Properties of Solids, Academia, Prague, Czech Republic, 1984.

[30] J. M. Criado, L. A. Pérez-Maqueda, and P. E. Sánchez-Jiménez, "Dependence of the preexponential factor on temperature," Journal of Thermal Analysis and Calorimetry, vol. 82, no. 3, pp. 671-675, 2005.

[31] L. M. Dyagileva, V. P. Mar'in, E. I. Tsyganova, and G. A. Razuvaev, "Reactivity of the first transition row metallocenes in thermal decomposition reaction," Journal of Organometallic Chemistry, vol. 175, no. 1, pp. 63-72, 1979.

[32] B. Janković, S. Mentus, and M. Janković, "A kinetic study of the thermal decomposition process of potassium metabisulfite: estimation of distributed reactivity model," The Journal of Physical Chemistry Solids, vol. 69, no. 8, pp. 1923-1933, 2008.

[33] A. Bhattacharjee, A. Rooj, M. Roy, J. Kusz, and P. Gütlich, "Solventless synthesis of hematite nanoparticles using ferrocene," Journal of Materials Science, vol. 48, no. 7, pp. 2961-2968, 2013. 

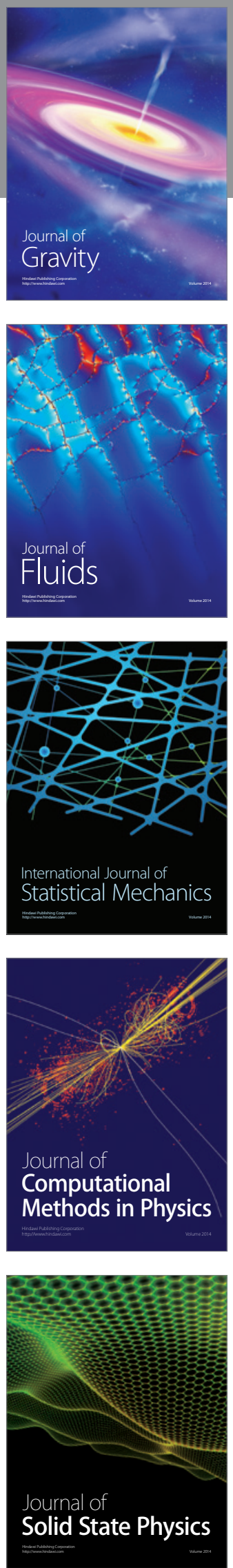

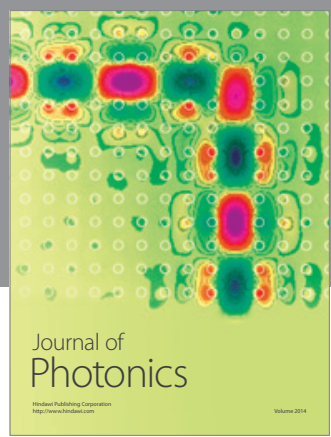

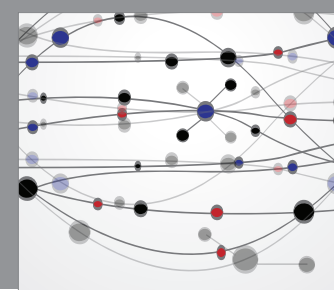

The Scientific World Journal

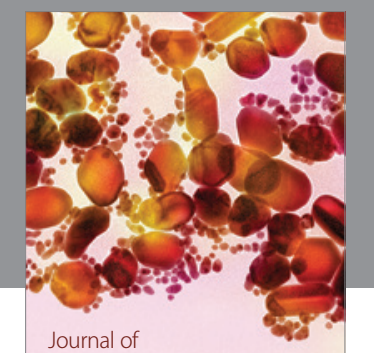

Soft Matter
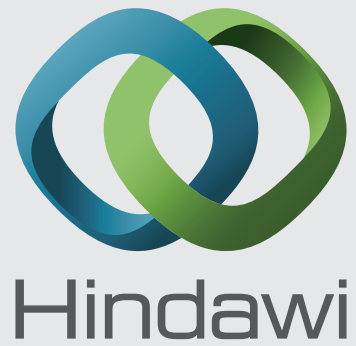

Submit your manuscripts at

http://www.hindawi.com
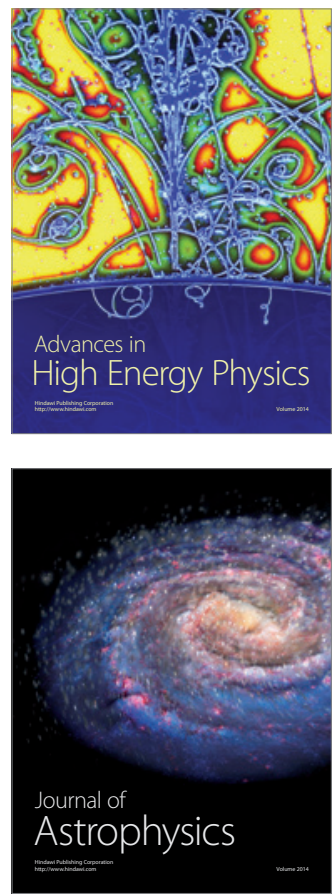
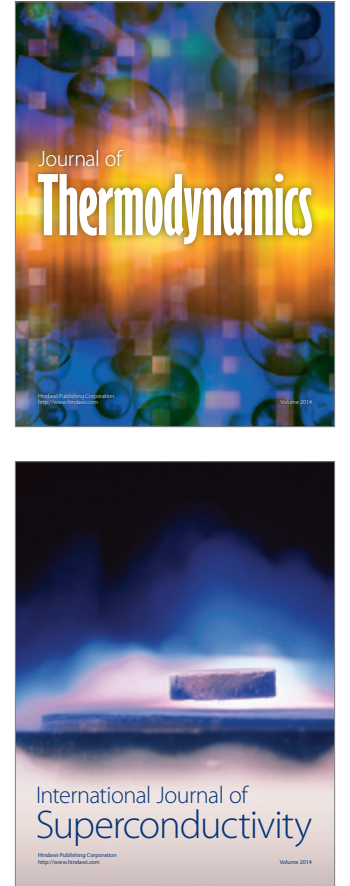
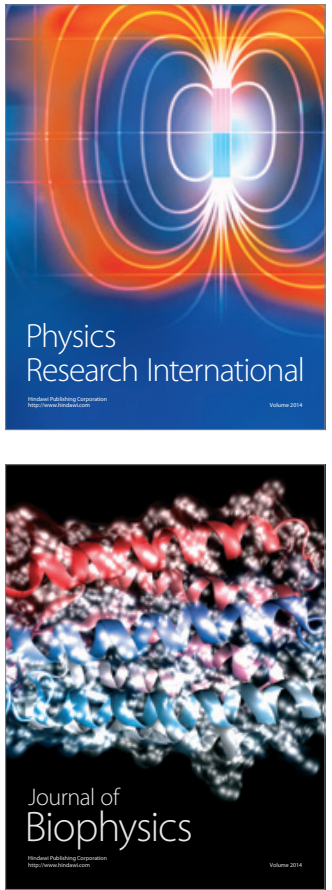
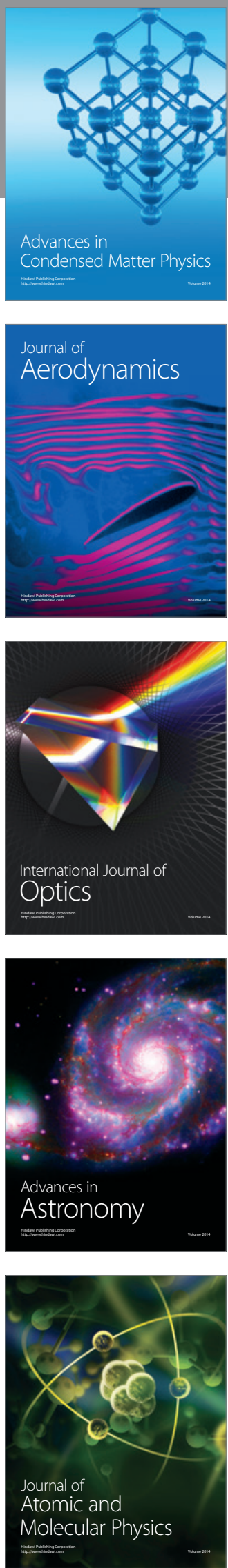